names for the protein they are describing is indeed a step in the right direction. Tony Smith

Oxford Dictionary of Biochemistry and Molecular Biology, 46 Stanley Hill Avenue, Amersham HP7 9BB, UK

\section{Cooperative efforts around Lake Tahoe}

Sir - The proposed Round Hill facility of the Desert Research Institute in cooperation with the University of Nevada, Reno, will be complementary to the University of California at Davis facility on the California side of Lake Tahoe, and will certainly not be a "duplicate" as suggested in the News story "University confronts new rival across Lake Tahoe" (Nature 400, 806; 1999).

Our Nevada facility will focus on atmospheric, ecological and hydro-geological research on processes in the forest environments surrounding the lake, whereas most Davis work has dealt primarily with processes in the lake. The Round Hill facility will also provide a location for integration of science, management and public policy.

The planning for Round Hill has been open, with details discussed in a series of public meetings since 1997. A memorandum of understanding was signed on 11 August 1999, in which the Desert Research Institute (DRI), University of Nevada, Reno (UNR), and Davis agreed to work with federal and state agencies to develop and implement a research agenda. This is not "competition" by Nevada scientists. The atmosphere is much more cooperative than suggested by the News story.

The notion that UNR and DRI scientists are newcomers to Tahoe basin research is not true. Nevada researchers have been studying the basin's ecosystems for decades, often in collaboration with Davis scientists. The Davis Tahoe Research Group, under the leadership of Charles Goldman, has also made significant contributions to our understanding of processes within the lake.

The proposed research facilities will be of benefit on two counts. First, the ecosystem is so complex that two research centres, one in Nevada and one in California, should speed the process of tackling the lake's environmental problems. Second, the US system of research funding is based on competition so that the best research is conducted. Although we anticipate collaboration on many projects, additional scientists competing for funds will increase the quality of research in the end.

Our goal is to provide excellent science that will allow public policy-makers to define and develop effective environmental management strategies. Nevada scientists support the excellent collaborative research programme developing at Lake Tahoe, which includes faculty members from Davis as well as researchers from national and international institutions. Our combined efforts will lead to an environmental management strategy to sustain the lake's beauty for the foreseeable future.

Stephen G. Wells ${ }^{\star}$, James S. Coleman ${ }^{\star}$, Joseph N. Crowley†, Kenneth W. Hunter Jr $\dagger$ ${ }^{*}$ Desert Research Institute, 2215 Raggio Parkway, Reno, Nevada 89512-1095, USA

$\dagger$ Office of the President, University of Nevada, Reno, Nevada 89557, USA

Rex Dalton, the author of the News article, stands by his story as an accurate description of the issues and competitive situation surrounding Lake Tahoe research. - Editor, Nature

\section{Precautionary approach to risk assessment}

Sir - The meeting of the World Trade Organization (WTO), which opens on 29 November in Seattle, Washington, will be a focal point for discussions about the social, economic and environmental implications of trade. Science has been given a central role in mediating disputes about the safety and environmental impact of new technologies. Our research indicates that the WTO will need to be both more rigorous and more precautionary in its use of regulatory science if it is adequately to address issues of sustainability.

First, there is the issue of product safety. Conventional probabilistic risk assessments play an important role in WTO rulings about the safety of new products, such as genetically modified (GM) foods and hormones used in animal production [see Briefing in this issue, pages 341-345]. In contrast, 'precautionary approaches' are often thought of as deviating from sound science.

Yet current risk assessments can only characterize some of the potential outcomes of the use of new products. Precautionary approaches, by acknowledging our incomplete knowledge of possible outcomes, and addressing the huge variation in the results of risk assessments, may actually enhance the rigour of scientific assessment. We developed this argument in The Politics of GM Food: Risk, Science and Public Trust (see www.gecko.ac.uk).

Second, there is the question of burdens of proof. WTO regulations and other international trade rules increasingly assume that new products are safe until proven otherwise: the burden of proof falls heavily on those who are worried about unforeseen or untested safety and environmental issues.

The debate about the safety of the bovine somatotropin (BST) growth hormone is a recent example. It has fallen to the European Union (EU) to provide evidence to support its doubts, rather than the producer of BST to demonstrate its safety. So the burden of proof falls on the regulator rather than the proponent of the technology. We believe that the burden of proof should be re-balanced through enhanced and transparent testing of new products, similar to the current method for testing and approving drugs. Likewise, there is a need for better scientific monitoring of the effects of new technologies once in use. Hormone-disrupting chemicals exemplify the issue of inadequate monitoring.

Assuming that products are safe until proven otherwise may lead to what can be described as 'soft disasters' - large-scale health and environmental problems that emerge slowly but at high cost to society. Such disasters mostly occur because excessive faith has been placed upon limited data about the safety of a product or process, ignoring many possible eventualities where there is little or no information.

It is now generally accepted that the assessment of risk in different social contexts can produce different - but equally valid - results based in science. Alternative assumptions, for example, are often adopted in different countries, partly as a result of varying social, economic and institutional conditions. But this calls into question the WTO's apparent assumption that the application of 'sound science' will lead to a single 'scientific' answer to complex questions of risk and safety. Further, to expect a uniform pattern of associated regulatory decisions is inconsistent with the well-established insights from risk assessment.

Such a desire for single, definitive answers is likely to generate increasing tension in the WTO, and undermine public confidence in its decisions. Public confidence will be vital if the advantages of liberalized global trade are to be sustained. A more effective way forward would be to pursue these issues through a precautionary approach within multilateral environmental agreements. Liability regimes also need to be strengthened as a safety net for those affected by 'soft disasters'. In this respect, the EU's recent extension of its strict liability laws to include agricultural products is to be welcomed.

These comments are based on research carried out within the Global Environmental Change Programme of the UK Economic and Social Research Council (ESRC).

Alister Scott*, Andy Stirling, Nick Mabey, Frans Berkhout, Chris Williams, Chris Rose, Michael Jacobs, Robin GroveWhite, Ian Scoones, Melissa Leach ${ }^{*}$ Corresponding author: ESRC Global Environmental Change Programme, Mantell Building, University of Sussex, Brighton BN1 9RF, UK 